\title{
DIVERSIDADE GENÉTICA DE NANNOTRIGONA TESTACEICORNIS LEPELETIER, 1836 (HYMENOPTERA, MELIPONINI) DA CHAPADA DIAMANTINA, BAHIA
}

\author{
Jade Cseko Nolasco Ribeiro ${ }^{1}$; Eddy José Francisco de Oliveira² \\ 1. Bolsista PROBIC/UEFS, Graduando em Bacharelado em Ciências Biológicas, Universidade Estadual de Feira de \\ Santana, e-mail: \\ jade.nolasco@ymail.com \\ 2. Orientador, Departamento de Ciências Biológicas, Universidade Estadual de Feira de Santana, e-mail: \\ eddyfo@gmail.com
}

PALAVRAS-CHAVE: uma; duas; três.

\section{INTRODUÇÃO}

A tribo Meliponini compreende as abelhas conhecidas como "abelhas indígenas sem ferrão", são encontradas em áreas tropicais e subtropicais do mundo, mas sua maior diversidade é observada nas regiões neotropicais (com mais de 300 espécies descritas) (Cotorpassi-Laurino et al., 2006). No Brasil, são descritas aproximadamente 192 espécies pertencentes a 27 gêneros (Silveira et al., 2002).

Nannotrigona testaceicornis é conhecida popularmente como Iraí. Trata-se de umas abelha que mede cerca de $4 \mathrm{~mm}$ de comprimento, é preta, possui pilosidade grisalha e asas esfumaçadas no terço apical (Monteiro, 2001). No Brasil essa espécie é encontrada nos estados da Bahia, Espírito Santo, Goiás, Mato Grosso do Sul, Minas Gerais, Paraná, Rio de Janeiro, Rio Grande do Sul, Santa Catarina e São Paulo (Moure; Urban; Melo, 2007).

Estudos com marcadores moleculares são capazes de fornecer informações sobre o nível de fluxo gênico entre as populações, detectar o efeito do fundador e gargalos populacionais e, estimar a expansão de território em relação à localização de supostos refúgios e zonas de expansão. O sistema de identificação por DNA Barcoding pretende identificar as espécies através da utilização de um pequeno segmento padronizado do DNA mitocondrial, concatenado com alguns genes nucleares. Esta abordagem representa uma estratégia extremamente promissora para o diagnóstico da biodiversidade (Herbert 2003).

Vários estudos com $N$. testaceicornis têm sido publicados com marcadores genéticos microssatélites (Oliveira et al, 2009); padrões de comportamento de postura, oviposição e aprovisionamento; análise do número de cromossomos; efetividade de polinização em acerola (Martins et al., 1999), morango (Maeta et al., 1992; Roselino et $a l ., 2004)$ e pepino (Ribeiro, 2004).

$N$. testaceicornis é uma espécie que possui características que a tornam um modelo interessante para um estudo filogeográfico, pois se trata de uma espécie com ampla distribuição geográfica que abrange uma diversidade de habitats, além de sua alta plasticidade adaptativa que a torna capaz de colonizar ambientes diversos. Uma abordagem filogeográfica com base em marcadores mitocondriais e nucleares possibilita estimar de forma indireta a origem e divergência de linhagens ou espécies. Dentro deste contexto teórico, este projeto propõe investigar a história evolutiva das populações de $N$. testaceicornis presente na Chapada Diamantina e compará-la com populações de diferentes localidades.

\section{MATERIAL E MÉTODOS OU METODOLOGIA \\ O Material biológico}


O material biológico a ser usado no trabalho, são amostras que foram coletadas no Parque Nacional da Chapada Diamantina, no Estado da Bahia. Além disso, foram estudadas amostras de 15 amostras dos estados de Espírito Santo, Goiás, Mato Grosso do Sul, Minas Gerais, Paraná, Rio de Janeiro, Rio Grande do Sul, Santa Catarina e São Paulo (área de distribuição da Nannotrigona testaceicornis). Todas as amostras encontram-se armazenas na coleção do Laboratório de Entomologia (LENT), situado na Universidade Estadual de Feira de Santana.

\section{Extração e amplificação do DNA}

Em laboratório procederemos com a extração do DNA total das amostras que foram armazenadas a $-20^{\circ} \mathrm{C}$, segundo o protocolo segundo Higuchi (1989) com algumas alterações. Para amplificação das regiões gênicas do DNA mitocondrial e nuclear, serão selecionados primers universais para abelhas, Citocromo Oxidase I (COI), Wingless (Wg) e Rhodopsin (Lr).

Tabela 1: Condições de PCR e pares de primes testados para a amplificação do mtDNA do gene COI. São mostrados: par de primers; principais genes contidos no fragmento; temperatura de anelamento

(TA); tamanho aproximado (em pares de bases) do produto amplificado e referências dos primers.

\begin{tabular}{|l|l|l|l|}
\hline $\begin{array}{l}\text { Par de } \\
\text { Primers }\end{array}$ & $\begin{array}{l}\text { Principais } \\
\text { genes }\end{array}$ & Sequência do oligonucleotídeo $-5^{\prime}$ '>3' & $\begin{array}{l}\text { TA } \\
\left({ }^{\circ} \mathrm{C}\right)\end{array}$ \\
\hline LCO1490 & COI & GGTCAACAAATCATAAAGATATTGG & 56 \\
\hline HCO2198 & COI & TAAACTTCAGGGTGACCAAAAAATCA & 56 \\
\hline LR143F & RHODOPSIN & GACAAACTKCCACCRGARATGCT & 56 \\
\hline LR639ER & RHODOPSIN & [Y]TTACCGRTTCCATCCRAACA & 56 \\
\hline WG578F & WINGLESS & TGCACNGTGAARAC[Y]TGCTGGATGCG & 56 \\
\hline WG1032R & WINGLESS & AC[Y]TCGCAGCACCARTGGAA & 56 \\
\hline
\end{tabular}

As reações de PCR irão ser realizadas em volume total de $25 \mu 1$ contendo $3 \mu 1$ de tampão Taq 10x com $\left(\mathrm{NH}_{4}\right)_{2} \mathrm{SO}_{4} ; 1 \mu \mathrm{l}$ de dNTP mix 2,5mM; $1 \mu 1 \mathrm{MgCl}_{2} 25 \mathrm{mM} ; 1 \mu 1$ de

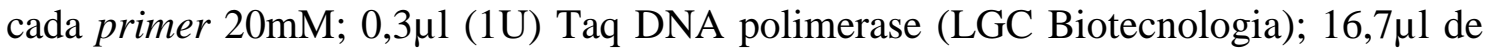
água ultrapura e $1 \mu 1$ de DNA total. A amplificação será conduzida em termociclador (Biocycler ${ }^{\circledR}$ - MJ96G) usando o seguinte programa: um ciclo de desnaturação a $94{ }^{0} \mathrm{C}$ com duração de 5 minutos, seguido de 35 ciclos de: desnaturação a $94^{\circ} \mathrm{C}$ por $1 \mathrm{~min}$, anelamento por 1 min e 20 segundos a $42^{\circ} \mathrm{C}$ e elongação por 1 min a $72^{\circ} \mathrm{C}$ e um ciclo de extensão final a $72^{\circ} \mathrm{C}$ por 20 min.

Os fragmentos amplificados foram submetidos à eletroforese em gel de agarose a $2 \%$, corado com Blue-Green ${ }^{\circledR}$ (LGC Biotecnology) em substituição ao método de brometo de etídio $(25 \mu \mathrm{g} / \mu \mathrm{l})$. Sendo utilizado na corrida de eletroforese um marcador de peso molecular de 100 pares de base (pb) Ladder (GE Healthcare®). Os fragmentos foram visualizados em transluminador e fotografados.

\section{Sequenciamento do DNA}

Os produtos da amplificação parcial dos genes foram purificados com o protocolo de precipitação de DNA com PEG a 20\%. Seguiremos então as reações de sequenciamento direto, em ambas as direções - foward e reverse - contendo: 50ng de produto de PCR purificado, 1,0 uL de tampão de sequenciamento (Save Money 5X), 0,5 uL de BigDye v3.1 (Applied Biosystems ${ }^{\circledR}$ ), 0,25uL do oligonucleotídeo (pmol/uL) iniciador e quantidade de água bidestilada estéril que complete $10 \mathrm{uL}$. Ao término da reação de sequenciamento, que consistiu de 35 ciclos compostos por uma etapa a $96{ }^{\circ} \mathrm{C}$ por $15 \mathrm{~s}$, uma etapa a $52{ }^{\circ} \mathrm{C}$ por $10 \mathrm{~s}$ e uma etapa de polimerização a $60{ }^{\circ} \mathrm{C}$ por $4 \mathrm{~min}$., as amostras foram mantidas a $4{ }^{\circ} \mathrm{C}$ até o momento do uso. Em seguida, $80 \mathrm{uL}$ de isopropanol foram adicionados a cada amostra. Após $15 \mathrm{~min}$. a temperatura ambiente, 
as amostras foram centrifugadas a $4.000 \mathrm{rpm}$, em centrífuga de placas Rotanta 46R (Hettich $\left.{ }^{\circledR}\right)$ com rotor para microplacas, por 45 min. a $20{ }^{\circ} \mathrm{C}$. Após precipitação do DNA, o sobrenadante irá ser descartado e as amostras lavadas, duas vezes, com $200 \mathrm{uL}$ de etanol $70 \%$ seguido de centrifugação a $4.000 \mathrm{rpm}$ por $15 \mathrm{~min}$. a $20{ }^{\circ} \mathrm{C}$, na mesma centrífuga Rotanta 46R. As amostras foram secas a vácuo, ressuspendidas em $10 \mathrm{uL}$ de formamida, desnaturadas por 5 minutos a $95{ }^{\circ} \mathrm{C}$ e submetidas ao sequenciamento em um sequenciador automático $\mathrm{ABI} 3130 \mathrm{XL}$ conforme metodologia sugerida pelo fabricante do equipamento (Applied Biosystems ${ }^{\circledR}$ ).

\section{Análises das Sequências}

Sequências "forward" e "reverse" de cada amostra foram comparadas, corrigidas e editadas, criando-se uma única sequência consenso para cada amostra, usando o pacote Staden (Staden et al. 1999) e alinhadas utilizando o programa Muscle versão 3.6 (Edgar, 2004).

A busca por sequências semelhantes às obtidas neste trabalho vai ser realizada através do programa BLAST (Altschul et al. 1990) no banco de dados do NCBI GenBank $^{\mathrm{TM}} \quad$ (http://blast.ncbi.nlm.nih.gov/Blast.cgi). Estas sequências serão disponibilizadas no NCBI GenBank ${ }^{\mathrm{TM}}$ ao final do trabalho.

\section{RESULTADOS E/OU DISCUSSÃO}

\section{Extração de DNA}

O atual método de extração (CCBD http://ccdb.ca/docs/CCDB_DNA_Extraction.pdf) em substituição ao método de fenolclorofórmio segundo Sambrook et. al (2001) foi mais eficaz e oferece risco reduzido de contaminação. Foram realizadas duas etapas de extrações, algumas amostras passaram pelas colunas de purificação. No total foram extraídos 50 indivíduos e amplificado para o gene Citocromo Oxidase I (COI) (figura 1).

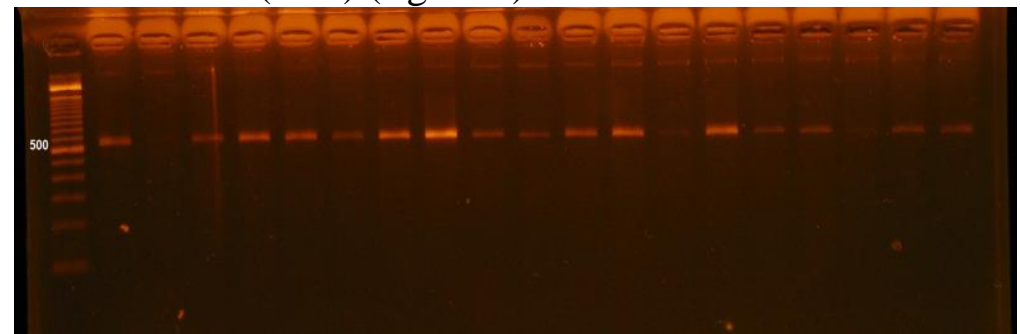

Figura 1. Gel de agarose 2\%, evidenciando a amplificação do DNA por PCR do gene COI de $N$. testaceicornis (20 indivíduos).

\section{Sequenciamento}

A partir das amplificações de 24 indivíduos dos tempos estudados, obtivemos 18 sequências com alta qualidade do gene COI. As demais sequências tiveram de baixa qualidade ou apenas uma das fitas (Forward ou Reverse) ficou disponível e informativa. Todas as amostras purificadas por colunas resultaram em melhores sequências.

Todas as sequencias foram confirmadas no NBCI como a espécie Nannotrigona sp (GenBank: EU163100.1). As sequências possuiram um tamanho variando entre 400 pb e $459 \mathrm{pb}$. Utilizamos um tamanho médio de $436 \mathrm{pb}$. Considerando o tamanho médio das sequências, observou-se 425 pares de pares conservados e 11 pb variáveis. Ao observar a composição nucleotídica das sequências, é possível identificar uma maior porcentagem de Adenina, seguida de Timina, Citosina e Guanina.

\section{Análise de Dados}

Observou-se que apesar de pequena, há diferenciação genética entre indivíduos de tempos diferentes. No dendograma é possível identifica a formação de dois grupos distintos por tempo estudado. (tabela 1, figura 2). 
Tabela 1. Distancia genética entre os tempos

\begin{tabular}{|l|c|c|c|c|c|}
\hline & 1 & 2 & 3 & 4 & 5 \\
\hline 1. Capotempo1 & & 0.00 & 0.01 & 0.01 & 0.01 \\
\hline 2. Capotempo2 & 0.00 & & 0.01 & 0.01 & 0.01 \\
\hline 3. Capotempo3 & 0.02 & 0.02 & & 0.00 & 0.00 \\
\hline 4. Capotempo4 & 0.01 & 0.01 & 0.01 & & 0.00 \\
\hline 5. Capotempo5 & 0.02 & 0.02 & 0.00 & 0.01 & \\
\hline
\end{tabular}

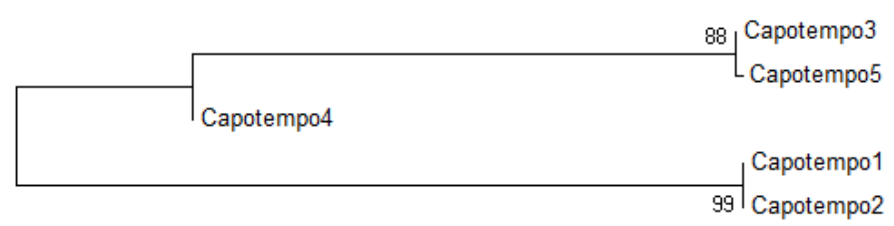

$\vdash_{0.001}$

Figura 2. Distancia genética entre os tempos

\section{CONSIDERAÇÕES FINAIS}

Este estudo fornece evidências para ratificar a já comprovada grande eficiência do DNA Barcode na identificação a nível de espécie, dando a oportunidade para estudos de diversidade genética em Meliponíneos. A partir dos achados no presente trabalho, faz-se necessário o uso desta ferramenta molecular nos demais estudos do LENT, uma vez que o DNA Barcode é bastante eficaz para a resolução de problemas como origem de populações, auxiliando ainda em estudos da história evolutiva dos demais grupos de insetos. Desta forma a resoluções dos demais genes auxiliará nos estudos desta espécie e sua distribuição na Chapada Diamantina.

\section{REFERÊNCIAS}

Altschul, S. F.; Gish, W.; Myers, E. W.; Lipman, D. J. Basic local alignment search tool. J. Mol. Biol. 215:403-410, 1990.

Camargo, J. M. F.; Pedro S. R. M. 1992. Systematic, phylogeny and biogeography of the Meliponinae (Hymenoptera, Apidae): a mini-review. Apidologie 23: 509-522.

Cortopassi-Laurino M, Imperatriz-Fonseca VL, Roubik DW, Dollin A, Heard T, Aguilar IB, Venturieri G, Eardley C, Nogueira-Neto P (2006) Global meliponiculture: challenges and opportunities. Apidologie, 37, 275-292.

Herbert, P. N. D. 2003. Biological Identifications through DNA Barcodes. Proc. R. Soc. Lond. B 270: 313-321.

Higuchi, R. 1989. Simple and rapid preparation of samples for PCR. In PCR technology (ed. H.A. Erlich), pp. 31-38. Stockton Press.

Maeta, Y.; Tezuka, T.; Nadano, H.; Suzuki, K. 1992. Utilization of the Brazilian stingless bee, Nannotrigona testaceicornis, as a polinizatior of strawberries. Honeybee Sci. 13: 71-78.

Martins, C. G. M.; Maria, C. A. L.; Baptista, J. L. 1999. Eficiência de tipos de polinização em acerola. Caatinga 12 (1/2): 55-59.

Monteiro, W. R. 2001. Meliponicultura - abelha Irai (Nannotrigona testaceicornis). Mensagem Doce 60.

Moure, J. S.; Urban, D.; Melo, G. A. R. 2007. Catalogue of Bees (Hymenoptera, Apoidea) in the Neotropical Region. Curitiba: Sociedade Brasileira de Entomologia. 1058p. 
Nogueira-Neto, P. 1997. Vida e criação de abelhas indígenas sem ferrão. Editora Nogueirapis, São Paulo.

Oliveira EJF, Freitas GS, Fonseca AS, Sousa ACB, Campos T, Assis AF, Souza AP, Contel EPB and Soares AEE (2009) Isolation and characterization of microsatellite markers from the stingless bee Nannotrigona testaceicornis. Conserv Genet Resour 1:97-99.

Ribeiro, A. de M. F. 2004. Polinização entomófila em cultivares híbridos de pepino (Cucumis sativus L.): pioneiro, safira e yoshinarim no campo e em estufa. Jaboticabal/SP. Tese de doutoramento apresentada a Universidade Estadual Paulista. $77 \mathrm{p}$.

Roselino, A. C.; Bego, L. R.; Santos, S. A. B. 2004. Pillonation of strawberry Fragaria X Anassa var. Camarosa, by Scaptotrigona aff depili and Nannotrigona testaceicornis (Hymenoptera, Meliponini). Proceedings of the $8^{\text {th }}$ IBRA International Conference on Tropical Bee and VI Encontro sobre Abelhas. 670P

Savard JL, Clergeau P, Mennechez G. 2000. Biodiversity concepts and urban ecosystems. Landscape and Urban Planning, 48, 131-142.

Silveira, F. A.; Melo, G. A. R.; Almeida, E. A. B. 2002. Abelhas Brasileiras, Sistemática e Identificação. Belo Horizonte: Silveira. 251 pp.

Standen, R.; Beal, K. F.; Bonfiel, J. K. The Staden package. Methods in Molecular Biology, 132:115-30, 1999. 